\title{
Shakespeare: el punto de vista ético
}

\author{
María Enriqueta Gonzélez Padilla \\ Universidad Nacional Autónoma de México
}

En el decurso de los tiempos, Shakespeare ha sido acusado de ateísmo o al menos de agnosticismo porque en apariencia su producción carece de un punto de vista ético claro y definido. Por lo tanto, se sacan a relucir lo profano y lo obsceno que con tanta frecuencia salpican sus obras, y en cuestiones de moral se le considera una especie de "dilettante" sin preocupaciones éticas y enamorado sólo de su profesión teatral.

Entre los severos mentores que delataron al dramaturgo se pueden señalar al doctor Samuel Johnson y a George Bernard Shaw. El primero se queja de cómo Shakespeare "sacrifica la virtud a la conveniencia" y se preocupa más "de agradar que de instruir" (Milward 1973). En cuanto a Shaw —que no es por cierto un autor que pudiéramos llamar edificante-, sus prefacios resuenan con frases que acusan al dramaturgo de falta de filosofía, de conciencia, de ideas constructivas, de contenido intelectual coherente.

Con todo, lo que califican críticos como Johnson y Shaw de defecto, es considerado por otros como cualidad, como señal de universalismo, como prueba de que la grandeza de Shakespeare radica en que pinta en sus muchos y variados personajes la naturaleza humana tal cual es, sin juzgarla, dicen, según normas pre-establecidas y rigoristas. Esta posición se ha visto influida por la tan traída y llevada doctrina del "arte por el arte", que es relativamente moderna.

Mi punto de vista al respecto es que la conciencia del bien y del mal es inherente al hombre y que el artista, aunque busque sólo deleitar y prescindir de lo ético, por esa misma opción "amoral", llamémosla así, incurre en una elección por lo que toca al problema y es responsable de ello. Los filósofos existencialistas nos han enseñado que el valor supremo del hombre es la libertad y que ésta se ejerce también cuando se decide "no decidirse", valga la redundancia. Pero fijémonos en algo muy revelador: ¿cuál era la opinión que prevalecía en la época de Shakespeare respecto a la moralidad o inmoralidad de la literatura? En todo caso debemos juzgar al dramaturgo 
según los criterios de su época, porque no se puede negar que él es hijo de su tiempo. Y he aquí que existía en el periodo isabelino un énfasis exagerado casi en el propósito moral de las obras de arte. El caso más elocuente y nítido en este sentido es sir Philip Sydney en su Defensa de la poesía. Al abogar por ella, el autor alude a que "sus efectos son tan buenos que enseñan la bondad causando deleite a quienes la aprenden" (1973: 217) y que en este sentido, el poeta aventaja al historiador y al filósofo. Algo semejante comenta Thomas Nash en su Pierce Penniless en un pasaje en que parece referirse a los dramas históricos, los cuales, dice, analizan toda suerte de vicios sólo por demostrar "cuan justo es Dios siempre en castigar el crimen" (1973: 217).

Pero volviendo con Shakespeare, cabe preguntarse qué tan acorde estaba él con estas opiniones. Hay que notar de antemano que para que exista una moral consistente en el teatro de nuestro dramaturgo no hay necesidad de que se haya formulado en su mente una teoría original al respecto. Basta con que se sigan los lineamientos generales de la moral cristiana tradicional, la cual se refleja en la expresión y en la fuerza imaginativa que la inspira. Las convicciones no se debilitan porque sean tradicionales; al contrario, se fortalecen cuando se aceptan con esa fe arraigada que inspira y modela la imaginación.

En las obras de Shakespeare prevalece una tendencia conservadora que favorece la tradición, al mismo tiempo que lo lleva por doquier a manifestar su disgusto por la novelería y por las apariencias. Ejemplos notables de ello son Osric en Hamlet (V,2) y Osvaldo en El rey Lear (II,2). Más aún, personajes protagónicos de sus obras, que probablemente fueron representados por el dramaturgo, usan expresiones que no dejan duda al respecto. Por ejemplo, en Como les plazca, el duque desterrado prefiere "la vieja costumbre" a la "afeitada pompa" de "la envidiosa corte" (II,1) y en Noche de Epifanía otro duque hace notar sus preferencias por "la vieja y antigua canción que oímos anoche" en contraste con los "aires ligeros y términos rebuscados de estos presurosos y acelerados tiempos" (II,4). Asimismo, en A buen fin no hay mal principio Lafeu dice del frívolo Parolles: "No puede haber pepita en esta nuez vana; el alma de este hombre radica en sus vestidos" (II,5).*

Por otra parte, en los dramas históricos, sobre todo cuando se analizan las dos tetralogías, se percibe la congruencia del pensamiento político de Shakespeare. De su conjunto se puede derivar una lección de primera importancia para el Estado: la necesidad de hacer prevalecer el orden moral.

* Todas las traducciones son de la autora de este artículo. 
Ejemplo claro de ello son los conflictos y disolución que traen consigo la ambición desmedida y la falta de escrúpulos de Ricardo III en contraste con el florecimiento que le brinda a Inglaterra el reinado de Enrique V.

Cuestión principal y recurrente de los dramas históricos es el dilema del individuo confrontado con un orden político que se sustenta en la injusticia y la usurpación. Tal es el problema de Hamlet en que llegan a su culminación muchos temas de los dramas históricos: si los que tienen autoridad violan el orden moral en asuntos que conciernen a su gobierno, ¿hasta qué punto deben sus súbditos obedecerlos? ¿Es legítimo rebelarse contra ellos? Y si lo es, ¿será también legítimo involucrar al país en revoluciones y derramamiento de sangre? Shakespeare encara estas cuestiones no de una manera frívola, ni simplemente para explotarlas desde el punto de vista de sus posibilidades dramáticas, sino con toda seriedad, mirando a lo que es recto y no meramente oportuno para conservar el orden público. De este modo investiga y penetra los resortes más íntimos de las acciones de sus personajes.

En cuanto al individualismo egoísta, el dramaturgo de plano lo aborrece y hace que se revistan de él los villanos y no los héroes de sus obras, v.gr., Ricardo de Gloucester, que dice: "[...] No tengo ni piedad ni amor ni miedo... Soy único" (Enrique VI, Parte III, V,6); Yago, que refiriéndose a Otelo comenta: "Al seguirlo únicamente me sigo a mí mismo" (I,1); o Edmundo que proclama: "Naturaleza tú eres mi diosa" (El rey Lear, I,2). Son hombres que se guían por la envidia, la ira o la ambición, aunque se expresen en términos poéticos, y su egoísmo queda reprobado dentro del desarrollo total de las obras. El ambicioso se aísla de sí mismo y de los demás, como Macbeth cuando confiesa después de matar a Duncan: "Al conocer lo que hice, sería mejor no conocerme a mí mismo" (III,2). Y al darse cuenta de que se siente constreñido, casi a pesar suyo, a continuar por el camino del crimen exclama: "Si no sigo vadeando, el regreso sería tan fastidioso como el seguir adelante" (III,4). En varias de sus tragedias Shakespeare muestra cómo el mal se multiplica hasta llenar el universo entero. Un ejemplo de ello es el reproche de Albany a Goneril por su falta de amor filial en El rey Lear (IV,2):

Si los cielos no envían pronto sus poderes visibles a reprimir estas viles ofensas, sucederá que la humanidad por fuerza se devore a sí misma como los monstruos del abismo. 
Por ello, no castigar el mal es desastroso. La cobardía recubre la úlcera, mientras "la corrupción, destruyendo sin ser vista, infecta todo", dice Hamlet (III,4).

La justicia exige el castigo del crimen lo mismo en los gobernantes que en los súbditos. El dramaturgo parece aprobar tanto la venganza de Hamlet como la severidad de Angelo en Medida por medida, pero pone en boca del duque en esta última obra palabras que exigen a quien deba castigar que sea "tan severo como santo" (III,2). El juez que condena a Claudio por fornicación, el implacable Angelo será convicto de un pecado aún mayor de concupiscencia contra la misma mujer que implora misericordia para su hermano. El pensamiento de Shakespeare en Medida por medida reverbera con los ecos del Sermón de la Montaña (Mateo vII, 1-2): "No juzguéis y no seréis juzgados... porque con la medida que midáis seréis medidos".

Además es un hecho que el arrepentimiento satisface las exigencias de la venganza y se hace acreedor al perdón del castigo, por lo cual el duque, una vez más en Medida por medida, se disfraza de fraile y visita a los culpables en la cárcel, enseñándole a Julieta a examinar su conciencia y a Claudio a afrontar la muerte con entereza.

La doctrina del perdón de las ofensas: "Yo os digo: amad a vuestros enemigos; haced el bien a los que os persiguen y calumnian, para que seáis hijos de vuestro Padre que está en el cielo (ibid., v, 43-45) y las palabras del Padre Nuestro: "Perdona nuestras ofensas así como nosotros perdonamos a los que nos ofenden" (ibid., VI, 12), son ilustradas dramáticamente obra tras obra, al grado de que la aceptación o el rechazo del perdón determina el desenlace, feliz o desdichado, como comedia o como tragedia. Así sucede en Los dos caballeros de Verona y en Como les plazca. En esta última el ofendido Orlando, tras de ser expulsado de casa por su hermano Oliverio, encuentra una oportunidad inesperada de tomar venganza de él en el bosque; pero en lugar de hacerlo, salva la vida de su hermano y queda herido de gravedad en el proceso. De ahí que Oliverio se convierta y la obra termine con el feliz casamiento de los dos hermanos.

El tema del perdón no es exclusivo de las comedias, sino que brilla de modo especial en las tragedias: después del duelo fatal, Hamlet intercambia el perdón con Laertes; las últimas palabras de Ofelia son una plegaria para que Dios se apiade de todas las almas cristianas; tras de ser estrangulada por Otelo, Desdémona emplea el último aliento de vida que le queda en un intento de encubrir el crimen de su esposo y en enviarle un recuerdo a su "bondadoso señor" $(v, 2)$, y en cuanto a Cordelia, ella se olvida de la injuria que sufrió de parte de su padre y rebosa piedad por sus padecimientos. Su disponibilidad a perdonar nos hace evocar al padre en la parábola del Hijo Pródigo: 
¿Y te aviniste, padre mío?

a albergarte con puercos y vagabundos

sobre la paja rala y húmeda? (IV,7)

En paralelo a Cordelia se halla Edgardo, que tampoco abriga rencor contra su padre por las ofensas del pasado, sino que lo va guiando hasta salvarlo del suicido. Además, por su paciencia en la adversidad y en la persecución, ilustra la última bienaventuranza: "Benditos los que sufren persecución por la justicia" (Mateo v, 10).

Las virtudes de Cordelia y de Edgardo, su espíritu misericordioso, su paciencia y mansedumbre, su pureza, su sed de justicia, hallan eco en los personajes de los últimos dramas, como Hermonia en El cuento de invierno y Próspero en La tempestad.

La moral de Shakespeare, opina Milward (1973: 26), puede con toda propiedad resumirse en la palabra "amor", la que "los barbasgrises llaman divina" (como dice Ricardo de Gloucester en Enrique VI, Parte III, V,6) y ha hallado su mejor definición en I Corintios XIII, 4-8). Este amor no es el Eros pagano, sino el Ágape cristiano: "El amor es paciente, es servicial; la caridad no es envidiosa, no es jactanciosa; no se engríe; es decorosa; no busca su interés; no se irrita; no toma en cuenta el mal; no se alegra de la injusticia; se alegra con la verdad. Todo lo excusa. Todo lo cree. Todo lo espera. Todo lo soporta. La caridad no para nunca".

Pero ambos, Ágape y Eros, hallan su culminación y su expresión simbólica en el sacramento del matrimonio que cierra con broche de oro muchas obras. De ahí que La comedia de las equivocaciones y La fierecilla domada estén salpicadas con ecos de la enseñanza de San Pablo respecto al matrimonio en Efesios $\mathrm{V}$.

Para Shakespeare, la relación del hombre y la mujer en el matrimonio no es un contrario casual que se pueda disolver a voluntad de cualquiera de las partes, sino "un lazo eterno de amor" (Noche de Epifanía, v,1), un sacramento de "fe y lealtad constante" (Enrique $V$, II,2). Es símbolo del lazo que mantiene unida a toda la creación, y sin el cual todas las cosas caerían en el caos original.

El hecho de que Shakespeare introduzca pasajes obscenos, personajes impúdicos o escenas de burdel como en las comedias de Falstaff o en Medida por medida, no significa que traicione su criterio moral. Falstaff, por ejemplo, es divertido e ingenioso a más no poder, pero sus desórdenes en los dos dramas de Enrique IV lo tornan gradualmente feo y repugnante, hasta que su comportamiento queda sancionado como punible por el Príncipe, que se refiere a él como "ese reverendo Vicio, esa Iniquidad gris, ese Padre 
Rufián, esa Vanidad entrada en años" (Parte I, II,4). Y ese rechazo sin mezcla de sentimentalismo debe ser compartido por el público y por los críticos a quienes les conviene recordar lo que el Príncipe había dicho respecto de sus compañeros de parranda en el Enrique IV, I (I,2):

Os conozco a todos y por corto rato

apoyaré el humor desenfrenado

de vuestra ociosidad.

Con todo, imitaré en esto al sol, que permite que las bajas nubes contagiosas oculten al mundo su belleza, para que, cuando le plazca volver a ser él mismo, dándose a desear, sea más admirado, atravesando las sucias y repugnantes neblinas de los vapores que querían estrangularlo.

En cuanto a Medida por medida, el modo de vida que representan las escenas de burdel (II, 1 y III,3) no se ofrece como placentera alternativa a la moralidad estricta del matrimonio cristiano, sino como contraste sórdido a la resplandeciente castidad de las heroínas Isabela y Mariana. La intransigencia de la primera respecto a la lujuria de Angelo, y a pesar de que la vida de su hermano está de por medio, es instrumento importante para la restauración del orden.

Aunque Shakespeare matiza muy a fondo las ambigüedades y flaquezas de sus personajes y no presenta las cosas simplemente en blanco y negro, su criterio es firme, al grado de desaprobar, como en La tempestad (IV,1), el intercambio sexual entre novios comprometidos. Su ideal del amor y del matrimonio se conforma con las enseñanzas de Cristo y en todo mira a lo que concierne al bien común.

En contraste con el ideal de las comedias, el tema común de las tragedias es el desgarramiento del individuo y de la sociedad por falta de amor, lo que acarrea nada menos que el caos, palabra de significado mucho más fuerte entre los isabelinos que el que le damos hoy en día. En el caso de Hamlet, el precipitado matrimonio de su madre con su tío, en el cual el Príncipe percibe lo deficiente del amor de su madre hacia su primer esposo, el padre de Hamlet, crea una crisis moral en el joven que lo lleva a desear la muerte. Sus sentimientos de disgusto hacia el mundo, hacia las mujeres, hacia la humanidad toda; sus dudas, demoras y vacilaciones, todo procede de la misma causa: su percepción de la flaqueza de su madre. Se siente solo y su único consuelo es la amistad de Horacio que en parte le 
ayuda a sobrevivir hasta que alcanza un alto grado de reconciliación con su madre y con su destino.

Más grave aún es el desgarramiento de la personalidad de Otelo por la aparente infidelidad de su esposa Desdémona que lo conduce, instigado por Yago, a abjurar de su amor por ella. En el desenlace, cuando se da cuenta del engaño de que ha sido víctima, se instala en él el caos y el vacío moral:

¡Mi esposa! ¡mi esposa! ¿qué esposa? No tengo esposa.

¡Qué hora tan insoportable y llena de pesadumbre!

Creo que debería sobrevenir ahora un gran eclipse de sol y de luna, y que espantado el globo

debería bostezar por la alteración. $(\mathrm{v}, 2)$

Peor es aún el caso de Macbeth, porque ha consentido totalmente en la tentación de asesinar a su rey y señor, cortando así el lazo que lo unía con su soberano, aislándose de la compañía de los hombres de bien y prefiriendo seguir las instigaciones de su esposa cuya personalidad se desintegrará en la locura. A partir de su crimen sacrílego, Macbeth siente que

No hay nada serio para los mortales, todo son fruslerías;

el renombre y la gracia han perecido, se agota el vino de la vida y no quedan más que heces con que esta tumba pueda fanfarronear. (II,3)

Macbeth se da cuenta de que ha entregado "la joya eterna" de su alma al "enemigo común del hombre" (III,1) y que el engaño del demonio consiste en exigir una entrega total a sus seguidores sin darles nada sustancioso a cambio $(\mathrm{v}, 5)$. Para él, mas no para Shakespeare, la vida no es más que "una historia contada por un idiota, llena de ruido y furia que no significa nada" $(\mathrm{V}, 5)$.

Las consecuencias morales del rechazo del amor se revelan, en términos cósmicos, en El rey Lear y en Timón de Atenas. En el primero de estos dramas, después de rechazar el cariño de su hija menor y de ser a su vez rechazado por sus otras hijas a quienes ha dado todo lo que poseía, el indignado monarca convoca a los elementos naturales a salir de quicio, para protestar por el rompimiento de los vínculos que unían al padre con las hijas:

¡Bufad vientos y haced que estallen vuestras mejillas! ¡Enfureceos! ¡Bufad! ¡Vosotros, cataratas y huracanes, 
diluviad hasta que hayáis inundado

nuestros campanarios y sumergido sus veletas!

¡Vosotros, fuegos sulfúricos que transcurrís

raudos como pensamientos y sois precursores

de las centellas que hienden los robles, achicharrad mi cabeza blanca! ¡Y tú, trueno, que todo haces temblar, de un golpe arrasa la gruesa redondez del mundo, rompe los moldes de la naturaleza, y haz que de una vez se derramen todos los gérmenes que producen al hombre ingrato! (III,2)

De modo semejante, Timón, abandonado por todos sus amigos, los conciudadanos de Atenas, quisiera envolver a toda la humanidad en el caos e invoca a la tierra diciendo:

¿Madre común, tú,
cuyo vientre inconmensurable
y pecho infinito
produce y alimenta todo...
seca tu fértil y fecundo vientre,
y no dejes que engendre ya al hombre ingrato!

En el caso de Lear, al revés de Timón, cesa la tempestad tanto externa como interna, y el orden moral se restaura gracias al perdón y al cariño de Cordelia. La reconciliación entre ambos es una de las más conmovedoras del teatro universal, cuando el rey le dice a su hija buena:

Cuando me pidas la bendición, me arrodillaré

e imploraré tu perdón. (v,3)

Así se cierra el círculo de las tragedias y el amor humano se restaura con la bendición divina.

Cordelia será en más de un sentido el modelo de las heroínas de los últimos dramas de Shakespeare, en que el dramaturgo se ocupa de la relación entre padre(s) e hija. Tal es el caso de Perdita, de Miranda, de Marina y de Imogena, que rezuman constancia, fidelidad, amor filial y gratitud. La pena de la separación en la mayoría de los casos halla un amplio contrapeso en el gozo del reencuentro y la reunión definitiva, lo cual es visto no como efecto de algún poder meramente natural, sino de la gracia divina que obra en la 
naturaleza y es superior a ella. En El rey Lear Cordelia posee esta gracia al punto de que se la compara implícitamente con Cristo, que "redime la naturaleza de la maldición común" (IV,6). Las heroínas de las últimas obras también son instrumentos de esta gracia, por ejemplo, en El cuento de invierno tanto la virtuosa reina, Hermonia, como su hija Perdita son favorecidas por la acción de la Providencia que se deja sentir, primero, en la proclamación del oráculo de Apolo que declara la inocencia de Hermonia y en el castigo que el celoso Leones sufre al quedarse sin heredero, y luego, en la milagrosa restauración de Hermonia que es devuelta a Leontes tras de su larga penitencia de dieciséis años. Por último, en La tempestad, Fernando contempla a Miranda como una diosa cuya perfección lo deja maravillado. Mediante su proyectado matrimonio la gracia llueve del cielo no sólo sobre los dos novios, sino sobre todos los personajes de la obra, y todo vuelve a su lugar merced a la Providencia Divina y a la sabiduría de Próspero.

Entre las últimas obras de Shakespeare hay una que se rige aparentemente por criterios paganos. Tal es Antonio y Cleopatra, donde el protagonista traiciona los compromisos del honor y del deber público por satisfacer su pasión con una mujer que huelga con él como prostituta. El drama culmina con los suicidios del héroe y de la heroína, y el movimiento general de la obra como que tiende a glorificar este amor ilícito, Milward observa que precisamente por eso el héroe parece "reivindicar la moralidad del Superhombre nietzcheano, tal como ésta se esboza en el Hércules del drama renacentista" (1973: 235). Con todo, hay que tener en cuenta que dentro de la estructura de esta obra romana, Shakespeare está desarrollando la concepción del amor romántico hasta sus últimas consecuencias para poner de manifiesto hasta dónde puede llegar la autoafirmación de los amantes. El que los críticos se identifiquen con ellos como se han identificado con Ricardo III, Falstaff, Macbeth o Edmundo, no significa que el dramaturgo también lo haga, por más que el lenguaje figurado posea la vastedad y el esplendor meramente superficiales del mundo material.

El desenlace de Antonio y Cleopatra tiene antecedentes en la tragedia de Romeo y Julieta, cuya pasión ardiente es censurada por el sabio fraile, cuando le advierte a Romeo: "Estos deleites violentos tienen finales violentos" (III, 6).

Y en efecto, la impresión que muchos espectadores tienen del saldo de esta vorágine juvenil es la de un terrible desperdicio por tantas vidas cortadas en flor: Romeo, Julieta, Mercucio, Teobaldo, Paris.

En Troilo y Crecida el héroe menosprecia la razón, y anticipándose al amor de Crecida declara: 
Una tal pasión rodea mi pecho que late mi corazón más fuerte que un pulso afiebrado, y todos mis poderes pierden el dominio de sí mismos como el vasallaje que desprevenido encuentra el ojo de la majestad. (III,2)

En consecuencia, el resultado de su actitud es, como dice el Soneto 129, "el desgaste del espíritu en un páramo de vergüenza".

En Coriolano hallamos un acucioso estudio psicológico del protagonista, que es renombrado por su nobleza y el valor no menos que por su orgullo y fiero enojo. Su problema es que busca la grandeza descuidando los intereses de la comunidad. Terminará como "dragón solitario" (IV,1), víctima de los enemigos de su patria con quienes se había aliado y a quienes después traiciona.

En Julio Cesar, que es una obra de ambiente precristiano, Bruto y Casio terminan suicidándose. Con todo, ambos finales trágicos van acompañados de expresiones de desaprobación. La más contundente de ellas es el parlamento de Bruto que dice:
Hallo cobarde y vil
por temor a lo que pueda suceder
restringir el período de la vida;
armándome con paciencia
para esperar el designio
de algunos poderes superiores
que nos gobiernan aquí abajo. $(\mathrm{V}, 1)$

En Hamlet, el protagonista experimenta la tentación del suicidio, como consta en sus soliloquios; pero después de haber navegado por un mar de tribulaciones, en el desenlace confiesa: "Hay una divinidad que moldea nuestros destinos por más que con rudeza nos empeñamos en destruirlos" $(\mathrm{V}, 2)$.

$Y$ en El rey Lear, tras de intentar arrojarse al mar desde un acantilado, el desgraciado Gloucester, que ha sido salvado por Edgardo, resuelve "soportar" la aflicción hasta que ella misma exclame: "Basta, basta" (IV,6), y más tarde, hallando de nuevo a su padre asediado por malos pensamientos, Edgardo le dice:

Los hombres deben soportar su partida de este mundo 
igual que su llegada a él.

todo consiste en estar preparados. $(\mathrm{V}, 2)$

Para terminar diremos que de principio a fin prevalece en las obras de Shakespeare la insistencia en la búsqueda de la realidad detrás de las apariencias y de lo verdadero por encima de lo falso y ostentoso. Éste es su propósito, ya se trate de los dramas históricos y de las tragedias como de las comedias y las obras romanas. Este propósito, que se define de más en más en términos del conocimiento de uno mismo de acuerdo con la tradición homilética que procede de la Edad Media lo mismo que de los clásicos grecolatinos y de Montaigne, es en verdad el pivote de las grandes tragedias con su penetrante análisis de la psicología del pecador. El conocerse tal como se es en realidad conduce al arrepentimiento y al perdón. Tal es el caso de Lear que descubre su relación con todos los hombres, en particular con los pobres, miserables y desnudos que no viven protegidos por las comodidades y la pompa del mundo. Finalmente, en su reconciliación con lo mejor de sí mismo, Lear reencuentra a su hija, figura cristológica, y gracias a su bondad adquiere el espíritu de arrepentimiento que es la condición del perdón, porque como diría San Pablo: "Todos hemos pecado y necesitamos de la gracia de Dios" (Romanos III,23).

Bibliografía

Milward, Peter. 1973. Shakespeare's Religious Background. Chicago: Loyola University Press.

Shakespeare, William. 1957. The Complete Works. Ed. de W. J. Craig. Oxford University Press.

Ubieta, José Ángel y colaboradores. 1976. Biblia de Jerusalén. Bilbao: Desclée de Brouwer. 